\title{
Effects of propafenone on calcium current in guinea-pig ventricular myocytes
}

\author{
${ }^{1}$ C. Delgado, J. Tamargo, *D. Henzel \& *P. Lorente
}

Institute of Pharmacology and Toxicology (CSIC), School of Medicine, Universidad Complutense, 28040 Madrid, Spain and *U 195 INSERM, School of Medicine, BP 38 Place Henri Dunant, 63001 Clermont Ferrand, France

1 The modulation of L-type voltage-sensitive calcium channels in guinea-pig isolated ventricular myocytes by propafenone was examined by the whole cell voltage-clamp technique.

2 Propafenone, $10^{-7}-5 \times 10^{-5} \mathrm{M}$, produced a concentration-dependent inhibition of $\mathrm{Ca}$ current $\left(I_{\mathrm{Ca}}\right)$ without any significant change in the current-voltage relation. Half-blocking concentration $\left(\mathrm{IC}_{50}\right)$ of propafenone for the peak $I_{\mathrm{Ca}}$ at $+10 \mathrm{mV}$ was $5 \times 10^{-6} \mathrm{M}$.

3 The voltage-dependence of $I_{\mathrm{Ca}}$ inactivation was shifted in the hyperpolarizing direction in the presence of $5 \times 10^{-6} \mathrm{M}$ propafenone.

4 A frequency-dependent relative block by propafenone was observed after repetitive depolarizing test pulses at a frequency of 0.5 and $1 \mathrm{~Hz}$. The recovery of $I_{\mathrm{Ca}}$ from inactivation was prolonged by propafenone and the reactivation exhibited an additional exponential component attributed to the slow release from drug block of $\mathrm{Ca}$ channels.

5 These results suggest that propafenone, at therapeutic concentrations exhibits Ca channel blocking properties that may be involved in its antiarrhythmic mechanism.

Keywords: Propafenone; calcium current; patch-clamp; ventricular myocytes

\section{Introduction}

Propafenone hydrochloride is an antiarrhythmic drug widely used for the management of supraventricular and ventricular arrhythmias (Harron \& Brogden, 1987; Funck-Brentano et al., 1990). The drug has demonstrated a high affinity for binding to the inactivated state of the $\mathrm{Na}$ channel with a kinetic profile similar to flecainide and encainide (Kohlhardt et al., 1983; Honjo et al., 1989; Valenzuela et al., 1989). In addition, propafenone has special properties that set it apart from the other class I antiarrhythmic agents. Thus, propafenone exhibits a consistent $\beta$-adrenoceptor blocking action in vitro (Hapke \& Prigge, 1976; Delgado et al., 1985; Kroemer et al., 1989) and in vivo (Müller-Pelzer et al., 1983) as well as possible calcium-channel blocking properties. As a matter of fact, propafenone exerts a clear negative inotropic effect (Dukes \& Vaughan Williams, 1984; Delgado et al., 1985) and at therapeutic concentrations depresses the slow action potentials elicited in fibres partially depolarized with $\mathrm{K}^{+}$(Ledda et al., 1981; Delgado et al., 1985). Moreover, using the voltage-clamp technique some authors have reported that propafenone also reduces the slow inward $\mathrm{Ca}$ current in rabbit sino-atrial cells (Satoh \& Hashimoto, 1984) and ventricular cardiac muscle fibres (Kohlhardt, 1977). Furthermore, experiments on rat isolated aortae have demonstrated that propafenone inhibits $\mathrm{Ca}$ entry through voltage- and receptor-operated channels as well as $\mathrm{Ca}$ release from intracellular stores, which again suggests that propafenone may exert $\mathrm{Ca}$ channel blocking properties in vascular smooth muscle (Carron et al., 1991).

All these results suggest that propafenone inhibits the slow inward current $\left(I_{\mathrm{Ca}}\right)$ in cardiac cells; however, detailed studies of the inhibitory effect of propafenone on $I_{\mathrm{Ca}}$ have not yet been performed in cardiac cells. Therefore, the present study was undertaken to elucidate the possible $\mathrm{Ca}$ channel blocking effect of propafenone by the use of single cardiac cells isolated from guinea-pig ventricles.

Our results show that propafenone blocks $I_{\mathrm{Ca}}$ with both

\footnotetext{
${ }^{1}$ Author for correspondence.
}

concentration- and frequency-dependent characteristics, and that these effects are related to the high affinity of the drug for binding to the inactivated state of the channel.

\section{Methods}

\section{Cell isolation}

Single ventricular myocytes of the guinea-pig heart were obtained by enzymatic dissociation following the procedure described by Isenberg \& Klöckner (1982). Hearts were removed from previously heparinized (500 u, i.p.) guinea-pig weighing $400-600 \mathrm{~g}$, and mounted in a Langendorff perfusion system for retrograde perfusion of the coronary vascular bed. The heart was perfused at $10 \mathrm{ml} \mathrm{min}^{-1}$ with the following oxygenated solutions at $37^{\circ} \mathrm{C}$ : (1) HEPES Tyrode solution for $4 \mathrm{~min}$; (2) nominally calcium-free solution for 10 min; (3) nominally calcium-free solution containing $0.4 \mathrm{mg}$ $\mathrm{ml}^{-1}$ collagenase (Type II, Worthington) for $10 \mathrm{~min}$ and (4) modified 'KB' or 'Kraftbrühe' medium (Isenberg \& Klöckner, 1982) for another $10 \mathrm{~min}$ period. The hearts were removed from the Langendorff column, and the ventricles dissected and cut into small pieces which were placed in a beaker containing ' $K B$ ' solution and gently shaken to disperse the isolated cells. The resulting cell suspension was filtered through a $250 \mu \mathrm{m}$ nylon mesh and centrifuged at low speed $(20 \mathrm{~g})$. Finally, the cell pellet was stored in 'KB' medium for $1-2 \mathrm{~h}$. An aliquot of this cell suspension was placed in a recording chamber $0.5 \mathrm{ml}$ in volume attached on the stage an inverted microscope (Olympus IMT-2) and after an additional period of $20 \mathrm{~min}$, the bath superfusate was replaced with the $\mathrm{Ca}$-containing HEPES-Tyrode solution. Experiments were performed at room temperature $\left(22-26^{\circ} \mathrm{C}\right)$ on Ca-tolerant healthy ventricular myocytes identified by their rod-like, striated appearance.

\section{Recording techniques}

Voltage-clamp experiments were performed with the single pipette in the whole-cell configuration of the patch-clamp 
technique (Hamill et al., 1981) by using an Axopatch-1D patch-clamp system (Axon Instruments). Suction pipettes were made from $1.5-1.6 \mathrm{~mm}$ o.d. soft glass capillary tubing with a microprocessor-based patch pipette puller (P.80/PC, Sutter Instruments). The pipettes had a tip resistance of 1.5-3 Megaohms after backfilling with the experimental internal solution. During the experiments, membrane potential and current data were displayed on a storage oscilloscope (Tecktronix 2214). Series resistance was compensated after the seal was broken to provide the fastest capacity transient possible without ringing of the amplifier. With maximal current $(I)$ not exceeding $1 \mathrm{nA}$, the voltage drop error resulting from the residual series resistance (Rs) estimated by I.Rs (Halliwell et al., 1987), was less than $4 \mathrm{mV}$. Currents were filtered with an eight-pole low-pass Bessel filter at a cutoff frequency of $2 \mathrm{kHz}$, digitized, stored and analyzed on an compaq IBM AT 386/25 computer system using the pClamp software package version 5.1 (Axon Instruments, Burlingame, California, U.S.A.). Selected records were printed out with a laser printer (Hewlett Packard Laser Jet printer series II). The data were compensated for the liquid junction potential between internal and external solutions (about $3 \mathrm{mV}$ ). Each pulse protocol was applied at intervals longer than $30 \mathrm{~s}$ to avoid the frequency-dependent effect of propafenone.

\section{Solutions and drugs}

Composition of the HEPES-Tyrode solution was as follows (mM): $\mathrm{NaCl} 150, \mathrm{KCl} 5.4, \mathrm{CaCl}_{2} 1.8, \mathrm{MgCl}_{2} 1.0, \mathrm{NaHCO}_{3}$ $5.8, \mathrm{NaH}_{2} \mathrm{PO}_{4} 0.4$, glucose 5.5 and HEPES 5.0 (pH adjusted at 7.4 with $\mathrm{NaOH}$ ), and the solution was equilibrated with $100 \% \mathrm{O}_{2}$. The nominally calcium-free solution had the same composition as that of HEPES-Tyrode without $\mathrm{CaCl}_{2}$. The ' $\mathrm{KB}$ ' medium containing (mM): $\mathrm{KCl} 30, \mathrm{KH}_{2} \mathrm{PO}_{4} 10, \mathrm{MgCl}_{2}$. $6 \mathrm{H}_{2} \mathrm{O} 5$, taurine 15 , glutamic acid 70 , ethylene glycol bis(beta-aminoethyl ether) $\mathbf{N}, \mathbf{N}, \mathbf{N}^{\prime}, \mathbf{N}^{\prime}$-tetraacetic acid (EGTA) 0.5 , ATP 5 and $\mathrm{KOH} 30(\mathrm{pH}=7.3)$. Potassium currents were eliminated by inclusion of $\mathrm{Cs}^{+}$in the pipette solution and by removal of $\mathrm{K}^{+}$in the external solution after the whole-cell configuration was achieved. In addition, $15-30 \mu \mathrm{M}$ tetrodotoxin (TTX) was included in the external solution to block sodium current. The pipette internal solution consisted of (mM): $\mathrm{CsCl} 140, \mathrm{MgCl}_{2}$ 2, HEPES $10, \mathrm{CaCl}_{2}$ 1, EGTA 11, ATP 5 (pH adjusted to 7.2 with $\mathrm{CsOH}$ ). By use of these solutions $\mathrm{Ca}$ currents were effectively isolated from $\mathrm{Na}$ and $\mathrm{K}$ currents. In some experiments neither $\mathrm{Cs}^{+}$nor TTX was used and the composition of the internal filling solution was as follows (mM): $\mathrm{KCl} 150, \mathrm{MgCl}_{2}$ 1.0, HEPES 5, EGTA 5, ATP 5 (pH 7.2 with $\mathrm{KOH}$ ).

Propafenone hydrochloride (Knoll Ibérica) as a powder was initially dissolved in deionized water to make a stock solution $\left(10^{-2}-10^{-3} \mathrm{M}\right)$, and desired drug concentration was then obtained by adding a small amount of stock solution to the perfusate.

\section{Statistics}

Results are expressed as mean \pm s.e.mean and Student's $t$ test was used to determine the significance of differences between test and control values.

\section{Results}

\section{Blocking action of propafenone on $\mathrm{I}_{\mathrm{Ca}}$}

In order to determine the effects of propafenone on inward calcium current $\left(I_{\mathrm{C}_{2}}\right)$, ventricular cells were clamped at $-40 \mathrm{mV}$ to inactivate the sodium current and $150 \mathrm{~ms}$ depolarizing test pulses to $+10 \mathrm{mV}$ were applied at a basal rate of $0.03 \mathrm{~Hz}$. The peak $I_{\mathrm{Ca}}$ was related to the zero current level. Figure 1a illustrates the time course of the onset of the effect of propafenone $5 \times 10^{-6} \mathrm{M}$. Propafenone decreased the $I_{\mathrm{Ca}}$
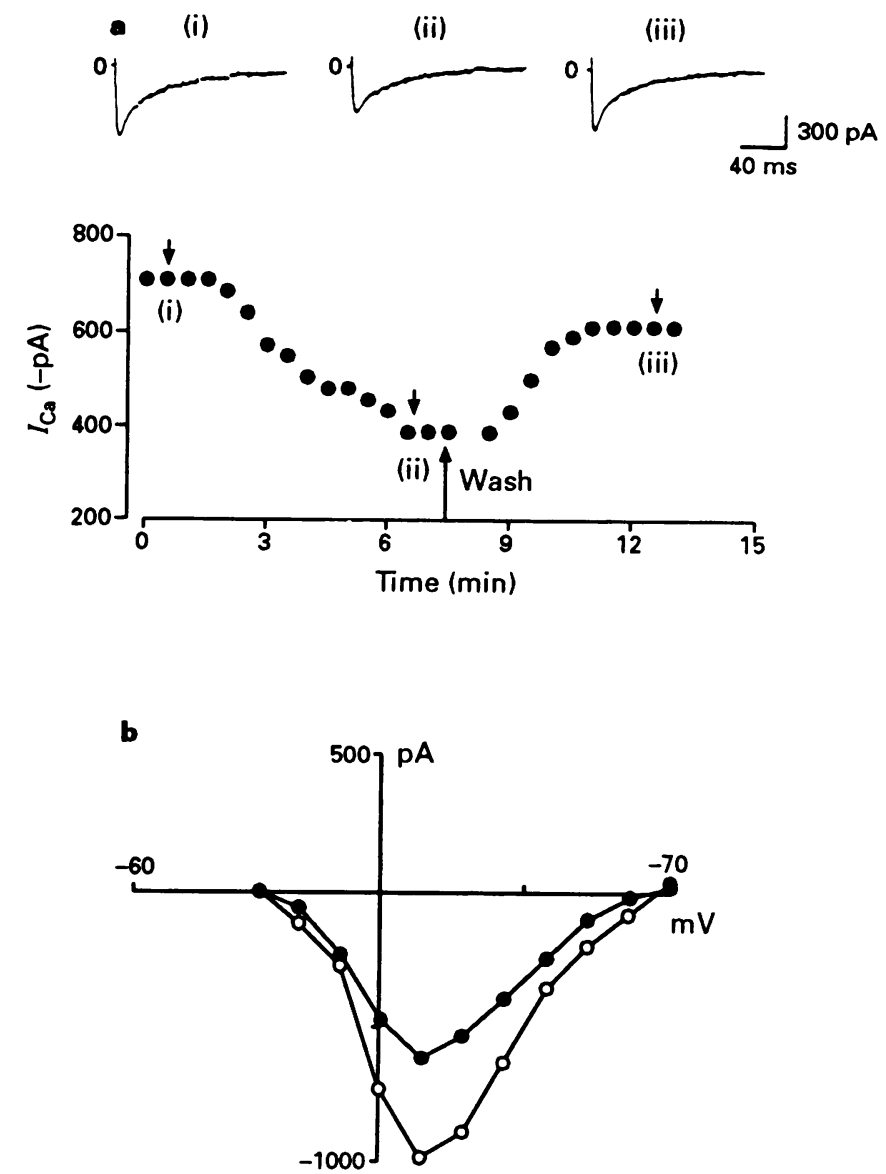

Figure 1 (a) Time course of the onset of the effects of propafenone $\left(5 \times 10^{-6} \mathrm{M}\right)$ on the inward current $\left(I_{\mathrm{Ca}}\right)$ elicited by depolarization from -40 to $+10 \mathrm{mV}$ at $0.03 \mathrm{~Hz}$. The external solution was zero $\mathrm{K}$. Patch pipette internal solution contained $\mathrm{CsCl}$. At the top of the figure, $I_{\mathrm{Ca}}$ values in control (trace $\mathrm{i}$ ), in the presence of propafenone (trace ii) and after washing (trace iii) are shown. The time course of the drug effects is shown below after the application in (ii) and after washout in (iii). (b) $I-V$ relationship of $I_{\mathrm{Ca}}$ obtained under control conditions $(\mathrm{O})$ and $7 \mathrm{~min}$ after application of propafenone $\left(5 \times 10^{-6}\right.$ M) (O). Depolarizing pulses of $150 \mathrm{~ms}$ in duration were applied from a holding potential of $-40 \mathrm{mV}$ to membrane potentials between -30 and $+70 \mathrm{mV}$.

within 1-2 min after beginning of the superfusion and its effects reached a steady state after $7 \mathrm{~min}$. At this time the cell was perfused with drug-free solution which was followed by a progressive recovery of current toward control, so that after 5 min the peak $I_{\mathrm{Ca}}$ reached approximately $80 \%$ of the control values $(619 \mathrm{pA}$ vs $710 \mathrm{pA})$. The differences observed at this time may occur under control conditions due to the 'run-down' of $I_{\mathrm{Ca}}$ which contributes in part to mask the recovery from blockade during washing.

To determine the effects of propafenone on current-voltage relationships $(I-V)$ of $I_{\mathrm{Ca}}, 150 \mathrm{~ms}$ depolarizing pulses were applied at a basal rate of $0.03 \mathrm{~Hz}$ from a holding potential of $-40 \mathrm{mV}$ to membrane potentials between -30 and +70 $\mathrm{mV}$. Peak amplitude of $I_{\mathrm{Ca}}$ was taken as the difference between the peak of the inward current and the current at the end of $150 \mathrm{~ms}$. Figure $1 \mathrm{~b}$ shows a typical $I-V$ relationship obtained under control conditions and $7 \mathrm{~min}$ after application of $5 \times 10^{-6} \mathrm{M}$ propafenone. In the absence of propafenone, the maximum peak inward current was obtained near $+10 \mathrm{mV}$ and the averaged peak amplitude of $I_{\mathrm{Ca}}$ at this potential was $813 \pm 53 \mathrm{pA}(n=30)$. Propafenone decreased the peak $I_{\mathrm{Ca}}$ (from $978 \mathrm{pA}$ to $606 \mathrm{pA}$ ) but it had no effect on the threshold potential $(-30 \mathrm{mV})$, the potential at which $I_{\mathrm{Ca}}$ was maximum and the apparent reversal potential (about 
$+65 \mathrm{mV}$ ), i.e., it had no effect on the shape of the relationship. Similar effects were obtained at all concentrations of propafenone tested.

Figure 2 shows the concentration-response plot for a wide range of propafenone concentrations. In these experiments peak $I_{\mathrm{Ca}}$ was obtained on depolarizations from $-40 \mathrm{mV}$ to $+10 \mathrm{mV}$ at $0.03 \mathrm{~Hz}$ and the peak $I_{\mathrm{Ca}}$ in control was taken as 1.0 and compared with the peak $I_{\mathrm{Ca}}$ measured $7 \mathrm{~min}$ after the beginning of drug superfusion. The average of $I_{\mathrm{Ca}}$ decrease produced by propafenone, $10^{-6} \mathrm{M}, 5 \times 10^{-6} \mathrm{M}, 10^{-5} \mathrm{M}$ and $5 \times 10^{-5} \mathrm{M}$ was $30.4 \pm 5.9 \%(n=6), 52.8 \pm 4.1 \% \quad(n=13)$, $62.5 \pm 8.5 \%(n=3)$ and $93.7 \pm 5.7 \%(n=7)$ respectively. Due to the very few experimental data points obtained, we could only approximate the $\mathrm{IC}_{50}$ value by interpolating the regression function obtained by least square analysis on experimental data with the relative $I_{\mathrm{Ca}}$ value $=0.5$. These results led to an approximate $\mathrm{IC}_{50}$ value of $5 \times 10^{-6} \mathrm{M}$. At concentrations up to $10^{-6} \mathrm{M}$ the washout of the cell with drug-free solution resulted in recovery of current toward control, while at $5 \times 10^{-5} \mathrm{M}$ no recovery was observed. Because of the estimated $\mathrm{IC}_{50}$ value, in the following experiments we selected the concentration of $5 \times 10^{-6} \mathrm{M}$ to analyze the effects of propafenone on $I_{\mathrm{Ca}}$.

\section{Tonic and frequency-dependent effects of propafenone}

A standardized protocol was used to evaluate the relative contribution of tonic blockade of $I_{\mathrm{Ca}}$ by propafenone. $I_{\mathrm{Ca}}$ was elicited by $150 \mathrm{~ms}$ depolarizing test pulses to $+10 \mathrm{mV}$ at $0.05 \mathrm{~Hz}$ from a holding potential of $-40 \mathrm{mV}$. After steadystate amplitude of $I_{\mathrm{Ca}}$ was obtained, depolarizing pulses were discontinued, drug was applied and, after a 3 min quiescent period, depolarizing test pulses were resumed. Tonic blockade was assessed as the difference in peak $I_{\mathrm{Ca}}$ in the control and the first pulse after drug exposure. In the experiment shown in Figure 3, propafenone produced very little inhibition of $\mathrm{Ca}$ current of the first clamp pulse after the quiescent period (from $560 \mathrm{pA}$ to $537 \mathrm{pA}$ ) but blockade increased with

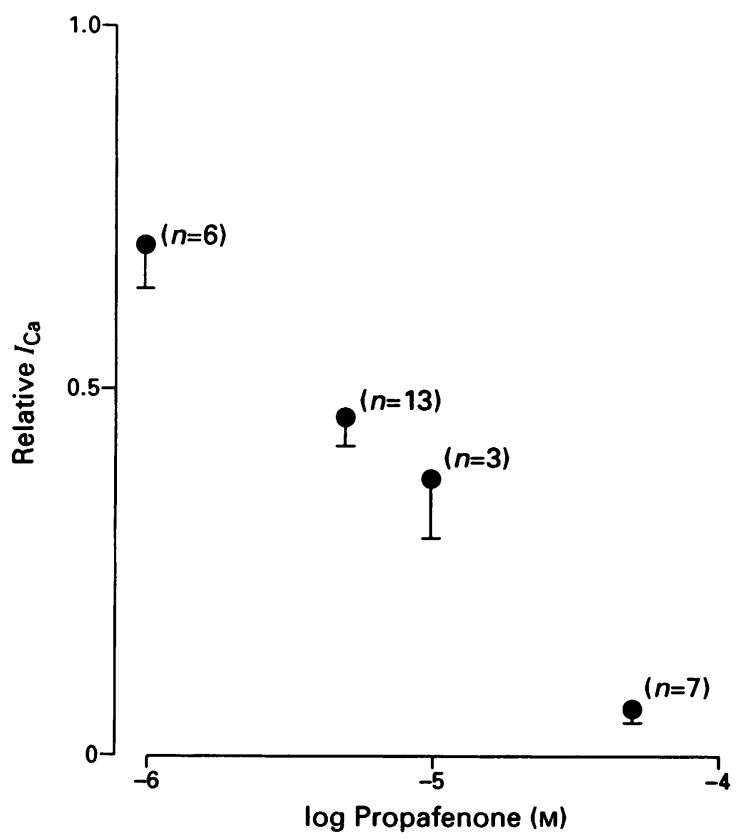

Figure 2 Dose-response plot of propafenone in single ventricular cells. $I_{\mathrm{Ca}}$ was elicited by depolarization from -40 to $+10 \mathrm{mV}$ at $0.03 \mathrm{~Hz}$. The peak $I_{\mathrm{Ca}}$ in control was taken as 1.0 and compared with the peak $I_{\mathrm{Ca}}$ measured $7 \mathrm{~min}$ after beginning the drug superfusion. The symbols and vertical bars indicate the mean and s.e.mean, respectively. The number of observations for each concentration is indicated in parentheses. The approximate $I_{50}$ was $5 \times 10^{-6} \mathrm{M}$.

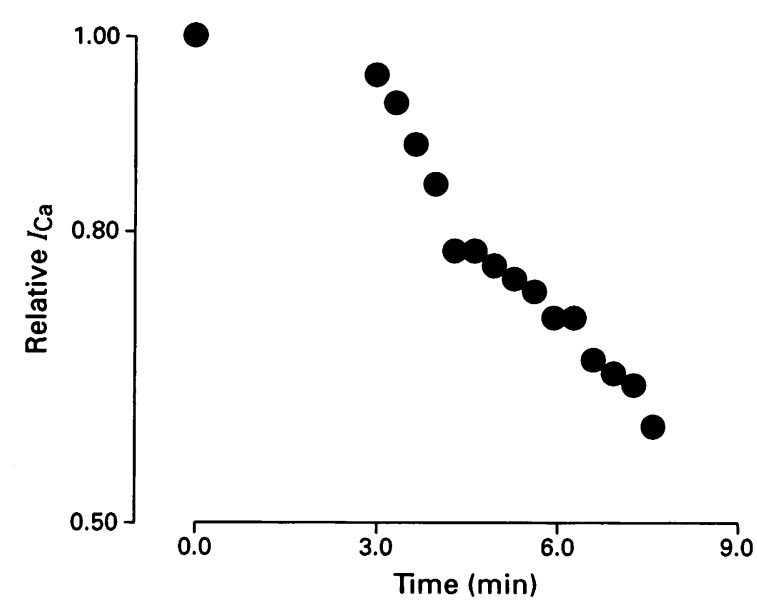

Figure 3 Relative contribution of tonic blockade of $I_{\mathrm{Ca}}$ by propafenone $\left(5 \times 10^{-6} \mathrm{M}\right)$. $I_{\mathrm{Ca}}$ was elicited by $150 \mathrm{~ms}$ depolarizing test pulses to $+10 \mathrm{mV}$ at $0.05 \mathrm{~Hz}$ from a holding potential of $-40 \mathrm{mV}$ until the peak $I_{\mathrm{Ca}}$ reached steady-state. At that moment depolarizing pulses were discontinued and drug was applied. After $3 \mathrm{~min}$ of quiescence, depolarizing test pulses were resumed. Peak $I_{\mathrm{Ca}}$ in the control was taken as 1.0 and compared with the peak $I_{\mathrm{Ca}}$ recorded after $3 \mathrm{~min}$ of quiescence.

repeated depolarizations. In six cells the averaged tonic block induced by propafenone $5 \times 10^{-6} \mathrm{M}$ was $6.9 \pm 1.6 \%$. These results suggest that propafenone shows a weak affinity for binding to the resting state of the calcium channel.

As previously described with other $\mathrm{Ca}$ channel blocking drugs (Ehara \& Kaufmann, 1978; McDonald et al., 1980; Trautwein et al., 1981; Pelzer et al., 1982; Lee \& Tsien, 1983; Uehara \& Hume, 1985) the inhibitory effect on $I_{\mathrm{Ca}}$ induced by propafenone was greatly enhanced by repetitive membrane depolarization, which indicated a large degree of frequency-dependent block. An example of such an experiment is illustrated in Figure 4, where the peak $I_{\mathrm{Ca}}$ associated with each pulse is plotted as a function of pulse number. In this cell 15 consecutive voltage-clamp pulses of $150 \mathrm{~ms}$ in duration, from a holding potential of $-40 \mathrm{mV}$ to a test potential of $+10 \mathrm{mV}$ were applied at 0.5 and $1 \mathrm{~Hz}(5 \mathrm{~min}$ between trains) in the absence and presence of $5 \times 10^{-6} \mathrm{M}$ propafenone. Frequency-dependent blockade was measured as the difference between peak $I_{\mathrm{Ca}}$ for the first and 15th pulses in control and after drug exposure. The results plotted in Figure 4 show that under control conditions the magnitude of the peak $I_{\mathrm{Ca}}$ declined after 15 pulses by $7 \%$ and $20 \%$ for 0.5 and $1 \mathrm{~Hz}$, respectively, probably because of an incomplete recovery of $I_{\mathrm{Ca}}$ from inactivation. However, in the presence of $5 \times 10^{-6} \mathrm{M}$ propafenone there was a dramatic decline in the peak $I_{\mathrm{Ca}}$ during the train of 15 depolarizing pulses $(57.1 \%$ and $82.8 \%$ for 0.5 and $1 \mathrm{~Hz}$ respectively). In 3 cells driven at 0.5 and $1 \mathrm{~Hz}$ propafenone decreased the $I_{\mathrm{Ca}}$ by $57.2 \pm 5.5(P<0.01)$ and $82.4 \pm 0.2(P<0.01)$, respectively.

\section{Effect of $5 \times 10^{-6} \mathrm{M}$ propafenone on the voltage- dependence of $\mathrm{I}_{C a}$ inactivation}

Because the $I_{\mathrm{Ca}}$ blockade by $\mathrm{Ca}$ channel blocking drugs can be modulated by membrane potential (McDonald et al., 1980; Hondeghem \& Katzung, 1984; Sanguinetti \& Kass, 1984), the interaction between propafenone block and calcium channel availability over a range of potentials was analyzed. For kinetic analysis of $I_{\mathrm{Ca}}$, all experiments were performed in zero $\mathrm{K}^{+}$external solution and in the presence of $15 \mu \mathrm{M}$ TTX and patch pipette contained $\mathrm{CsCl}$. The voltage-dependence of $I_{\mathrm{Ca}}$ availability was examined by use of a double-pulse protocol: $2 \mathrm{~s}$ conditioning pulses of variable amplitude $(-55$ to $+10 \mathrm{mV})$ which produced steady state 

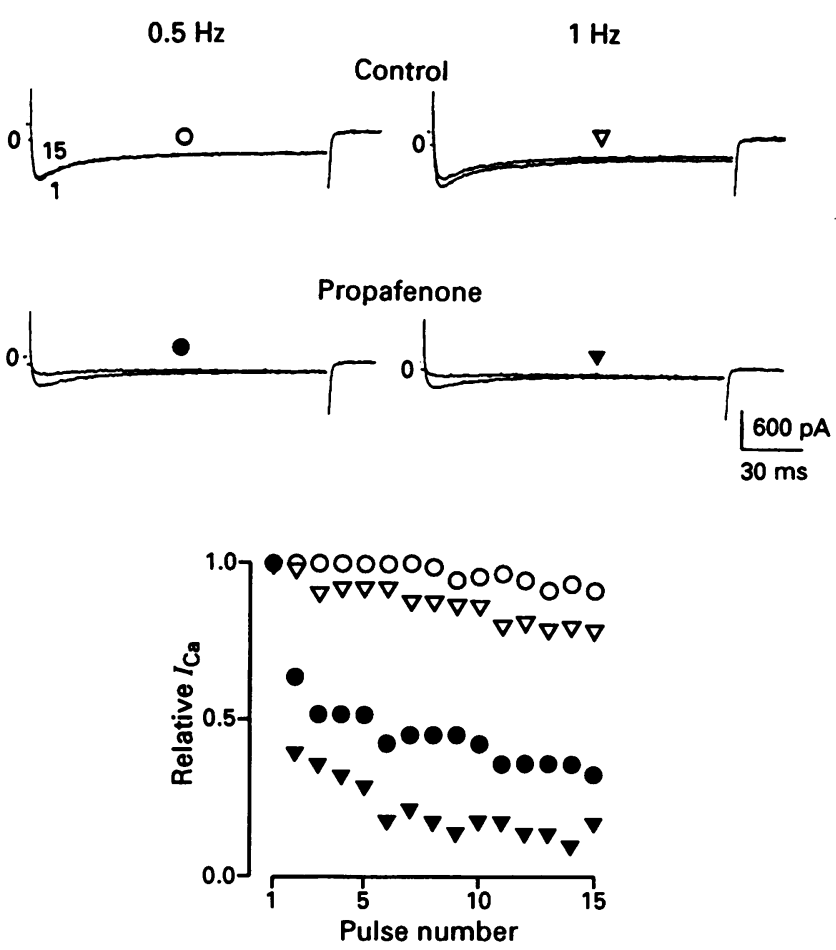

Figure 4 Effects of repetitive pulses at 0.5 and $1 \mathrm{~Hz}$ on the modulation of $I_{\mathrm{C}}$ by propafenone $\left(5 \times 10^{-6} \mathrm{M}\right)$. Fifteen depolarizing pulses of $150 \mathrm{~ms}$ duration were applied to $+10 \mathrm{mV}$ from a holding potential of $-40 \mathrm{mV}$ at the frequency of 0.5 (circles) and $1 \mathrm{~Hz}$ (triangles) during control (open symbols) and after drug superfusion (closed symbols). Upper panel shows current records for pulse 1 and 15 with and without the drug. Bottom panel summarizes the results of plotting normalized $I_{\mathrm{Ca}}$ values for individual pulse numbers. The external solution was normal Tyrode.

inactivation of $I_{\mathrm{Ca}}$ (Yatani et al., 1986) under control conditions were followed by a $10 \mathrm{~ms}$ return to the holding potential and a $150 \mathrm{~ms}$ test pulse to $+10 \mathrm{mV}$. Figure $5 \mathrm{a}$ shows a representative steady-state inactivation curve for $I_{\mathrm{Ca}}$. The data were fitted with a nonlinear least-squares regression analysis to a Boltzmann distribution (Hodgkin \& Huxley, 1952):

$$
I=I_{\max } /\left(1+\exp \left[\left(V_{\mathrm{m}}-V_{\mathrm{h}}\right) / K\right]\right)
$$

where $V_{\mathrm{h}}$ is the potential of half inactivation, $V_{\mathrm{m}}$ is the prepulse potential and $K$ is the slope factor of the curve. The curve was S-shaped, with conditioning pulses to more negative potentials being associated with greater $I_{\mathrm{Ca}}$ values. Propafenone $\left(5 \times 10^{-6} \mathrm{M}\right)$ decreased $I_{\mathrm{C}}$ at $-55 \mathrm{mV}$ from 697 to $368 \mathrm{pA}$ as expected from the concentration-response curve. Figure $5 \mathrm{~b}$ shows the resultant steady-state inactivation curves obtained after individual tail currents $\left(I_{\text {teet }}\right)$ were normalized to the tail currents elicited by conditioning pulse to $-55 \mathrm{mV}$ $\left(I_{\max }\right)$ and plotted against the conditioning potential. In this individual cell, propafenone shifted the $V_{\mathrm{b}}$ value from $-26.0 \mathrm{mV}$ to $-29.7 \mathrm{mV}$, while the slope factor was almost similar to the control value (4.5 vs 4.0 , respectively). The mean control value for $V_{\mathrm{h}}$ in 5 cells was $-25.3 \pm 0.8 \mathrm{mV}$ and in the presence of $5 \times 10^{-6} \mathrm{M}$ propafenone the curve shifted significantly in the hyperpolarizing direction with a mean value for $V_{h}$ of $-32.7 \pm 1.7 \mathrm{mV}(P<0.01)$. It is worth noting that no change in the slope factor of the curve under the two conditions was observed $(3.7 \pm 0.3$ during control and $3.9 \pm 0.6$, in the presence of propafenone, $n=5$ ).

The results suggest that propafenone possesses a high affinity for the inactivated state of the Ca channel. However, it is of interest to analyze the possibility as to whether propafenone can block calcium channels in the open state. In
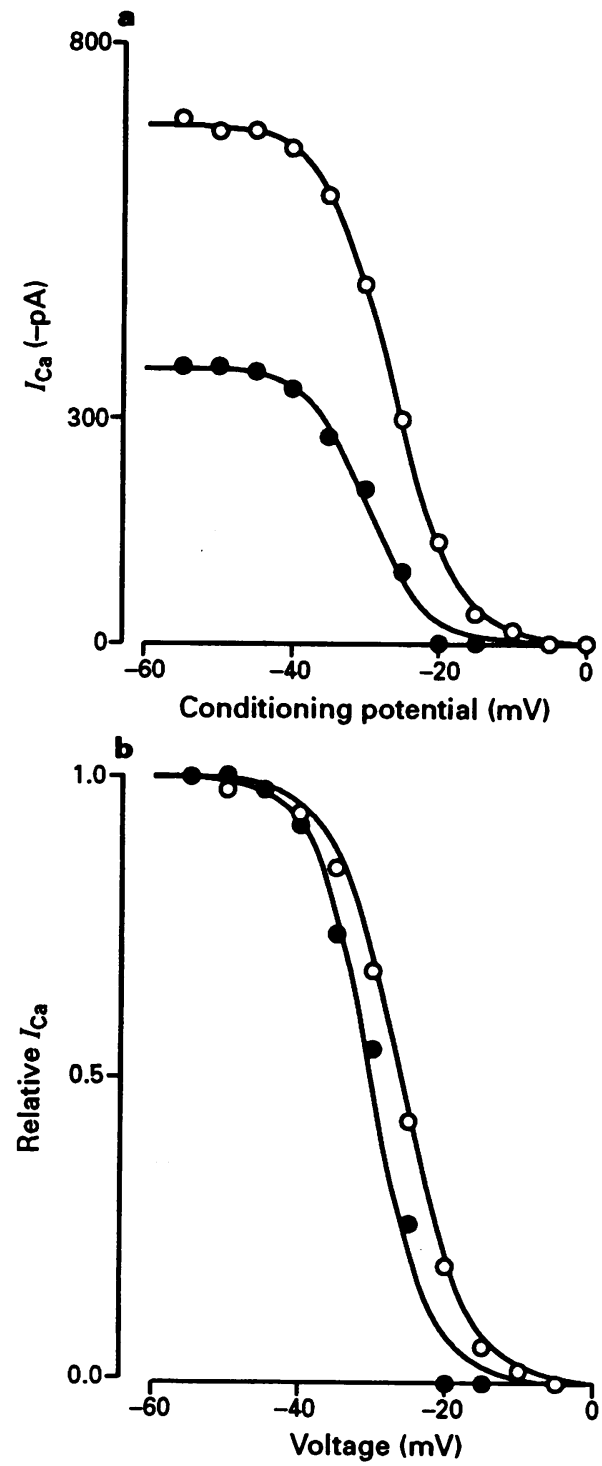

Figure 5 Effects of propafenone on the steady-state inactivation curve for $I_{\mathrm{Ca}}$. The membrane potential was held at $-40 \mathrm{mV}$. After the application of $2 \mathrm{~s}$ conditioning pulses to various levels ranging from -55 to $+10 \mathrm{mV}$ in $5 \mathrm{mV}$ steps, the membrane was depolarized to $+10 \mathrm{mV}$ for $150 \mathrm{~ms}$. (a) Shows the $I_{\mathrm{C}}$ values at individual conditioning potentials in control $(\mathrm{O})$ and after applying propafenone $\left(5 \times 10^{-6} \mathrm{M}\right)(\mathrm{O})$. In (b), the steady-state inactivation curve of $I_{\mathrm{Ca}}$ was constructed by normalizing the $I_{\mathrm{Ca}}$ values. The line drawn through the data points represents the equation:

$$
I=I_{\max } /\left(1+\exp \left[\left(V_{\mathrm{m}}-V_{\mathrm{b}}\right) / K\right]\right.
$$

Where $V_{\mathrm{h}}$ is the potential of half inactivation, $V_{\mathrm{m}}$ is the conditioning potential and $K$ is the slope factor of the curve. Under control conditions, $V_{h}=-26.0 \mathrm{mV}$ and $K=4.5$. After exposure to propafenone $\left(5 \times 10^{-6} \mathrm{M}\right), V_{\mathrm{h}}=-29.7 \mathrm{mV}$ and $K=4.0$.

the simplest case, in which the inactivated state is assumed to be absorbing, the open channel block can be measured by comparing the waveform of the currents during depolarizing voltage pulses before and after exposure to propafenone (Yantani et al., 1986). Drugs that bind to the open state of the channel have been shown to increase the inactivation rate of current through the channels during depolarizing voltage pulses after applying the drug (Lee \& Tsien, 1983; Colquhoun \& Hawkes, 1983). Figure 6a shows the time course of $I_{\mathrm{Ca}}$ before and after the application of propafenone $(5 \times$ $\left.10^{-6} \mathrm{M}\right)$. The $\mathrm{Ca}$ currents recorded with a faster time scale (Figure 6b) revealed that propafenone not only reduced the 
peak magnitude of the $I_{\mathrm{Ca}}$ but also hastens its decay. The relaxation process was well described by a double exponential fit. The fast time constant was similar in the presence and absence of propafenone $(5.1 \pm 0.3$ and $5.5 \pm 0.1 \mathrm{~ms}$, respec-

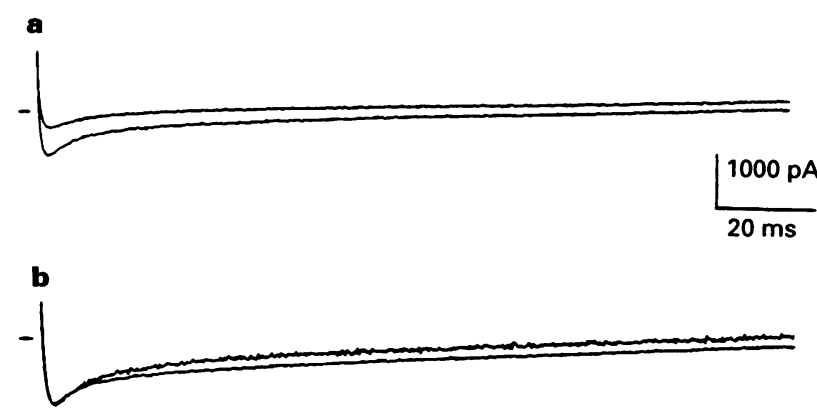

Figure 6 Effects of propafenone $\left(5 \times 10^{-6} \mathrm{M}\right)$ on the rate of inactivation of $I_{\mathrm{Ca}}$ during depolarizing voltage pulse. (a) Current records in response to $100 \mathrm{~ms}$ clamp step to $+10 \mathrm{mV}$ from a holding of $-40 \mathrm{mV}$ at a rate of $0.03 \mathrm{~Hz}$, control $(\mathrm{O})$ and after applying propafenone (O) are superimposed. (b) The current traces before $(O)$ and after applying propafenone $(O)$ were scaled and were superimposed to compare the inactivation time course of $I_{\mathrm{Ca}}$. The relaxation process was well described by a double exponential fit. The fast time constant was similar in the presence and absence of propafenone (5.1 vs $5.0 \mathrm{~ms}$ ) but the slow time constant was shortened by propafenone (42.8 vs $25.6 \mathrm{~ms})$.

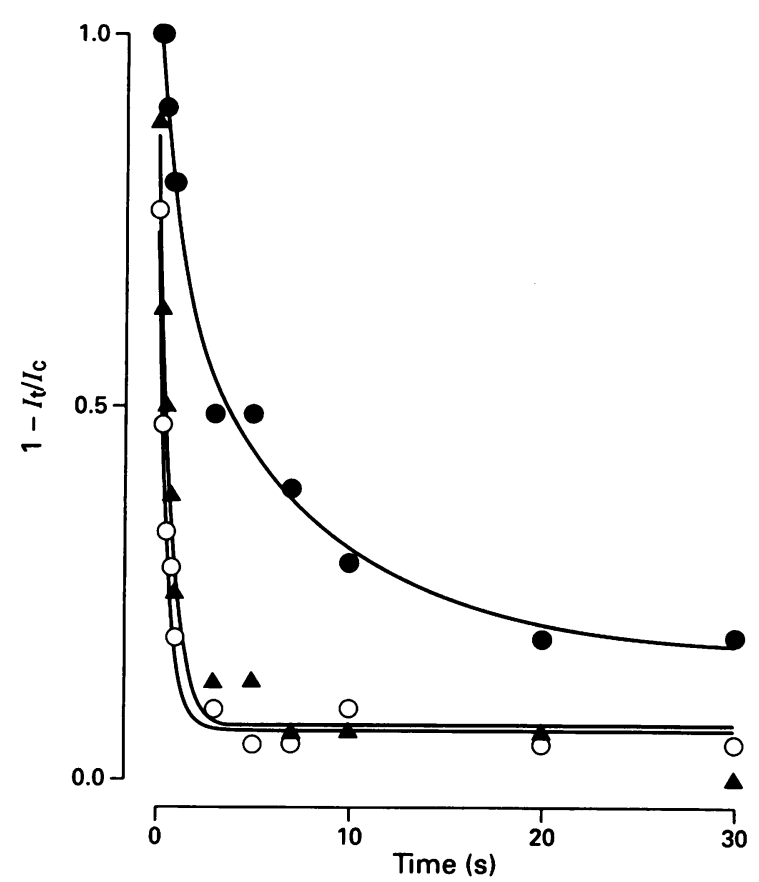

Figure 7 Effects of propafenone $\left(5 \times 10^{-6} \mathrm{M}\right)$ on the recovery of $I_{\mathrm{Ca}}$ A $2 \mathrm{~s}$ conditioning pulse which produced apparent inactivation at $+10 \mathrm{mV}$ was followed by a test pulse of $150 \mathrm{~ms}$ duration from a holding potential of $-40 \mathrm{mV}$ to $+10 \mathrm{mV}$ at various intervals (from $100 \mathrm{~ms}$ to $30 \mathrm{~s})$. The peak current for each test pulse $\left(I_{t}\right)$ was normalized to that for the control pulse applied $30 \mathrm{~s}$ before the conditioning pulse $\left(I_{\mathrm{c}}\right)$. The data were fitted by a least squares method of a sum of two exponentials: $y=A_{1} e^{-1 / r 1}+A_{2} e^{-t / r 2}$, where $y$ is the ratio of unrecovered current $\left(1-I_{t} / I_{c}\right)$. In the absence of propafenone $(O)$ the time course was best fitted by one exponential with a recovery time constant of $503 \mathrm{~ms}$. With propafenone $(0)$, the recovery of $I_{\mathrm{Ca}}$ was best fitted by two exponentials, $1100 \mathrm{~ms}$ and $8 \mathrm{~s}$ for the fast and slow components, respectively. After washout $(\Delta)$, the time course of recovery was again fitted by a single exponential, with a recovery time constant similar to the control $(658 \mathrm{~ms})$. tively, $n=6$ ) but the slow time constant was shortened by the drug $(41.3 \pm 1.6 \mathrm{~ms}$ in control and $26.9 \pm 1.9 \mathrm{~ms}$ in the presence of propafenone, $n=6, P<0.001$ ).

\section{Effects of propafenone on $\mathrm{I}_{\text {Ca }}$ reactivation}

The frequency-dependent blocking action of $I_{\mathrm{Ca}}$ observed in the presence of the drug suggested that the recovery from inactivation after depolarizing test pulse may also be slowed by propafenone. In order to examine this possibility the time course of recovery from inactivation of $I_{\mathrm{Ca}}$ was investigated by use of a double-pulse protocol. A $2 \mathrm{~s}$ conditioning prepulse which produced apparent inactivation at $+10 \mathrm{mV}$ was followed by a test pulse of $150 \mathrm{~ms}$ duration from a holding potential of $-40 \mathrm{mV}$ to $+10 \mathrm{mV}$ at various intervals (from $100 \mathrm{~ms}$ to $30 \mathrm{~s}$ ). The peak current for each test pulse was normalized to that for the control pulse applied $30 \mathrm{~s}$ before the conditioning pulse and is plotted as a function of the recovery period in Figure 7. In the absence of propafenone, the time course of recovery was best fitted by a single exponential function with a time constant of recovery $(\tau)$ of $503 \mathrm{~ms}$ while in the presence of $5 \times 10^{-6} \mathrm{M}$ propafenone the recovery process was markedly slowed being better described by two exponential functions (time constant of $1100 \mathrm{~ms}$ and $8 \mathrm{~s}$ for the fast and slow component respectively). The figure also shows that when the same experimental protocol was repeated after perfusing the cell with drug-free solution, the time course of recovery was again fitted by a single exponential which reached values similar to the control $(\tau=658 \mathrm{~ms})$. Similar findings were observed in another two cells. Then, it may be suggested that the slow component of the Ca current recovery with propafenone reflects the time course of drug dissociation from the inactivated $\mathrm{Ca}$ channel, whereas the fast component seems to reflect, at least in part, the recovery of drug-unbound channels from inactivation. The slow recovery of propafenone-bound channels from inactivation is consistent with the observation that propafenone produced a profound frequency-dependent $I_{\mathrm{Ca}}$ block even at $0.5 \mathrm{~Hz}$.

\section{Discussion}

The results of the present investigation provide evidence that L-type Ca channels of guinea-pig isolated ventricular myocytes are blocked reversibly by propafenone. This conclusion is based on the finding that this drug blocks in a concentration-dependent manner the calcium inward current activated from potentials positive to $-40 \mathrm{mV}$, the half-maximum inhibition $\left(\mathrm{IC}_{50}\right)$ occurring at a concentration of about $5 \times$ $10^{-6} \mathrm{M}$. At the holding potential used in this study most T-type Ca channels are inactivated (Bean, 1985; Mitra \& Morad, 1986), and thus the contribution of $I_{\mathrm{Ca}}$ through these channels can be ruled out. Propafenone reduced the peak amplitude of $I_{\mathrm{Ca}}$ without affecting the voltage-dependence of $\mathrm{Ca}$ channel activation or the slope factor of the inactivation curve. These results suggested that propafenone reduced the maximum conductance of $I_{\mathrm{Ca}}$. The finding that propafenone blocks $I_{\mathrm{Ca}}$ agrees well with previous studies on cardiac tissues in which at the same range of concentrations, propafenone produced concentration-dependent decrease of the $V_{\max }$ of the slow action potentials, a valid index of the $I_{\mathrm{Ca}}$ (Malecot \& Trautwein, 1987), both in guinea-pig ventricular muscle fibres (Delgado $e t$ al., 1985) and in dog Purkinje fibres (Malfatto $e t$ al., 1988). Moreover, voltage-clamp experiments on rabbit sinus node cells (Satoh \& Hashimoto, 1984) have demonstrated that propafenone inhibited the $I_{\mathrm{Ca}}$, but only at concentrations higher than $10^{-5} \mathrm{M}$. The discrepancy in the concentrations of propafenone required to inhibit the $I_{\mathrm{Ca}}$ can probably be attributed to the different methodology used (voltage-clamp vs patch-clamp and experimental protocols), even though species and/or tissue differences can also account for this discrepancy.

Furthermore, propafenone exerted voltage- and frequency- 
dependent blockade of $I_{\mathrm{Ca}}$. The inhibitory effects of a variety of $\mathrm{Ca}$ channel antagonists on myocardial $\mathrm{Ca}$ channels may be explained according to the modulated receptor hypothesis (Hondeghem \& Katzung, 1977; Hille, 1977a,b; Uehara \& Hume, 1985) which postulated that drug affinity for the Ca channel is modulated by channel state (i.e. rested, activated, inactivated). In the present experiments, propafenone produced little or no tonic $I_{\mathrm{Ca}}$ block, i.e. block of the $\mathrm{Ca}$ channels in the absence of stimulation, which indicated that it exhibits a low affinity for the resting state of the channels. In addition, the block of $I_{\mathrm{Ca}}$ by propafenone was markedly dependent on the frequency of stimulation. Use or frequencydependence block of $I_{\mathrm{Ca}}$ has been hypothesized to occur because depolarizing pulses cause channel to cycle between resting, open, and inactivated states. If the affinity of a drug is much greater for open and/or inactivated channels than resting channels, then significant drug binding may occur during depolarizing steps even though little drug was bound under resting conditions. If during a train of depolarizing pulses the time available between pulses is not enough to allow drug unbinding from the inactivated channels, then block will accumulate until a steady-state level is reached. In the present experiments propafenone shifted the steady-state $\mathrm{Ca}$ inactivation curve toward more negative potentials, which indicated that the block of $I_{\mathrm{Ca}}$ by propafenone is also modulated by membrane potential. This shift suggested that propafenone-induced blockade of $I_{\mathrm{Ca}}$ is more pronounced when the channels are in the inactivated state and thus, that it exhibits a higher affinity for the inactivated state than for the resting state of the Ca-channel. According to Bean et al. (1983), the shift in the middle point of the steady state availability curve $\left(V_{\mathrm{b}}\right)$ is related to the drug concentration and dissociation constants for binding to inactivated $\left(K_{\mathrm{l}}\right)$ and rested state channels $\left(K_{\mathrm{R}}\right)$ as follows:

$$
V_{\mathrm{h}}=K \ln \left[\left(1+[\mathrm{B}] / K_{\mathrm{R}} /\left(1+[\mathrm{B}] / K_{\mathrm{I}}\right)\right]\right.
$$

where $K$ is the slope factor of the inactivation curve $(K=4.0$ in Figure 5). Plugging in the shift $\left(\Delta V_{\mathrm{b}}\right)$ of $-7 \mathrm{mV}$ produced by $5 \times 10^{-6} \mathrm{M}$ propafenone in Figure 5 , along with the value for $K_{\mathrm{R}}$ from Figure 2, gives a value of $K_{\mathrm{I}}=5 \times 10^{-7} \mathrm{M}$ for 'binding' to the inactivated $\mathrm{Ca}$ channels.

The frequency-dependent block of $I_{\mathrm{Ca}}$ by propafenone can also be explained by a decrease in the recovery of inactivation. Several organic $\mathrm{Ca}$ antagonists have been shown to prolong the recovery from inactivation (Sanguinetti \& Kass, 1984; Uehara \& Hume, 1985). In the present study, the recovery process was slowed by propafenone being better described by a double exponential, the slower phase possibly indicating a slow dissociation of drug molecules from the inactivated Ca channels (Hondeghem \& Katzung, 1984; Uehara \& Hume, 1985). This finding can explain the marked use-dependent block of $I_{\mathrm{Ca}}$ induced by propafenone at slow

\section{References}

BEAN, B.P. (1985). Two kinds of calcium channels in canine atrial cells. J. Gen. Physiol., 86, 1-30.

BEAN, B.P., COHEN, C.J. \& TSIEN, R.W. (1983). Lidocaine block of cardiac sodium channels. J. Gen. Physiol., 81, 613-642.

CARRON, R., PEREZ-VIZCAINO, F., DELPON, E. \& TAMARGO, J. (1991). Effects of propafenone on ${ }^{45} \mathrm{Ca}$ movements and contractile responses in vascular smooth muscle. Br. J. Pharmacol., 103, 1453-1457.

COLQUOHOUN, D. \& HAWKES, A.G. (1983). The principles of the stochastic interpretation of ion-channel mechanisms. In SingleChannel Recording. ed. Sakmann, B. \& Neher, E. pp. 135-175. New York: Plenum Press.

CONOLLY, S., KATES, R., LEBSACK, C., HARRISON, D. \& WINKLE, R. (1983). Clinical pharmacology of propafenone. Circulation, 68, 589-596.

COURTNEY, K.R. (1987). Review: quantitative structure/activity relations based on used-dependent block and repriming kinetics in myocardium. J. Mol. Cell. Cardiol., 19, 319-330. frequencies of stimulation $(0.5$ and $1 \mathrm{~Hz})$. However, it cannot explain by itself the shift of the inactivation curve to more negative potentials as the slope factor remains unchanged. On the other hand, within the context of a modulatedreceptor hypothesis, the kinetics of $I_{\mathrm{Ca}}$ recovery for drugs that are predominantly charged at physiological pH are slower than for drugs that are predominantly neutral (Hille, $1977 \mathrm{~b}$; Uehara \& Hume, 1985). The apparent $\mathrm{p} K_{\mathrm{a}}$ of propafenone has been calculated as 9.0 (Courtney et al., 1987) and is similar to that of $\mathrm{D}-600\left(\mathrm{p} K_{\mathrm{a}}=8.6\right)$ (Uehara \& Hume, 1985 ) indicating that both drugs are predominantly charged at physiological $\mathrm{pH}$. In addition, this property suggests that propafenone must cross the cell membrane to gain access to its site of action (Hescheler et al., 1982). Further experiments will be necessary to prove this possibility.

Finally, the concentration of propafenone used in this study $\left(10^{-6} \mathrm{M}-5 \times 10^{-5} \mathrm{M}\right)$ included not only the therapeutic plasma levels $\left(482 \mu \mathrm{g} \mathrm{I}^{-1}-1812 \mu \mathrm{g}^{-1}\right.$ : $1.3 \times 10^{-6} \mathrm{M}-5.3 \times$ $10^{-6} \mathrm{M}$; Keller et al., 1978; Karaguezian et al., 1983; Connolly et al., 1983) but also the toxic plasma level of drug. Therefore, the observed $I_{\mathrm{Ca}}$ block produced by propafenone may be responsible for some of its cardiodepressant effects as well as for its antiarrhythmic effectiveness on supraventricular arrthythmias. Propafenone can depress cardiac automaticity (Tamargo \& Delgado, 1985) and marked bradycardia, sino-atrial block and sinus arrest have been reported after the administration of propafenone (Connolly et al., 1983; Schlepper, 1987). On the other hand, Honjo et al. (1989) found that propafenone at concentrations $>10^{-6} \mathrm{M}$ shortened action potential duration in single ventricular myocytes from guinea-pig and this shortening was accompanied by an attenuation of sarcomere shortening during twitch contraction suggesting that the $\mathrm{Ca}$-antagonist effect of propafenone could be involved. Furthermore at high concentrations in vitro, propafenone exerted a negative inotropic effect in isolated atrium or ventricle compatible with calcium-channel blockade (Dukes \& Vaughan Williams, 1984; von Philipsborn et al., 1984). Moreover, since the $I_{\mathrm{Ca}}$ plays a major role in both conduction and automaticity of the A-V node, the marked frequency-dependent $I_{\mathrm{Ca}}$ block appears also to be important to explain the clinical effectiveness of propafenone against paroxysmal and non-paroxysmal $A-V$ nodal reentrant tachycardia (Funk-Brentano et al., 1990).

In conclusion, the present data demonstrate that in guineapig ventricular myocytes propafenone produces a concentration-dependent inhibition of $I_{\mathrm{Ca}}$ which can be involved in its antiarrhythmic mechanism.

We thank Knoll-Made for the generous gift of propafenone. This work was supported by a research grant from the CICYT (PM880009), DGICYT (MEC) of Spain and the DGICYT of France.
DElGaDO, C., TAMARGO, J. \& TEJERINA, T. (1985). Electrophysiological effects of propafenone in untreated and propafenone pretreated guinea-pig atrial and ventricular muscle fibres. Br. J. Pharmacol., 86, 765-775.

DUKE, I. \& VAUGHAN WILLIAMS, E. (1984). The multiple modes of action of propafenone. Eur. J. Cardiol., 5, 115-125.

EHARA, T. \& KAUFMAN, R. (1978). The voltage and time-dependent effects of (-) Verapamil on the slow inward current in isolated cat ventricular myocardium. J. Pharmacol. Exp. Ther., 207, 4955.

FUNCK-BRENTANO, C., KROEMER, H.K., LEE, J.T. \& RODEN, D.M. (1990). Propafenone. N. Engl. J. Med., 22, 518-525.

HALLIWELL, J.V., PLANT, T.D. \& STANDEN, N.B. (1987). Voltage clamp techniques. In Microelectrode Techniques. ed. Standen, N.B., Gray, P.T. \& Whittaker, M.J. pp. 13-28. Cambridge: Company of Biologists. 
HAMILL, O.P., MARTY, A., NEHER, E., SAKMANN, B. \& SIGWORTH F.J. (1981). Improved patch-clamp techniques for high resolution current recording from cells and cell-free membrane patches. Pflügers Arch., 391, 85-100.

HAPKE, H.J. \& PRIGGE, E. (1976). Zur Pharmakologie von 2'[Hydroxy-3-(propylamino)-propoxy]-3-phenyl-propiophenon (Propafenon, SA 79)-hydrochlorid. Arzneimittel Forschung, 26, 1849-1857.

HARRON, W.G. \& BROGDEN, N. (1987). Propafenone. A review of its pharmacodynamic and pharmacokinetic properties, and therapeutic use in the treatment of arrhythmias. Drugs, 34, 617-647.

HESCHELER, J., PELZER, D., TRUBE, G. \& TRAUTWEIN, W. (1982). Does the organic calcium channel blocker D-600 act from inside or outside on the cardiac cell membrane? Pflügers Arch., 303, 287-291.

HILLE, B. (1977a). The pH-dependent rate of action of local anesthetics on the node of Ranvier. J. Gen. Physiol., 69, 475-496.

HILLE, B. (1977b). Local anesthetic: hydrophilic and hydrophobic pathways for drug-receptor reaction. J. Gen. Physiol., 69, 497515.

HODGKIN, A.L. \& HUXLEY, A.F. (1952). A quantitative description of membrane current and its application to conduction and excitation in nerve. J. Physiol., 117, 500-544.

HONDEGHEM, L.M. \& KATZUNG, B.G. (1977). Time- and voltagedependent interactions of antiarrhythmic drugs with cardiac sodium channels. Biochim. Biophys. Acta, 472, 373-398.

HONDEGHEM, L.M. \& KATZUNG, B.G. (1984). Antiarrhythmic agents: the modulated receptor mechanism of action of sodium and calcium channel-blocking drugs. Annu. Rev. Pharmacol. Toxicol., 24, 387-423.

HONJO, H., WATANABE, T., KAMIYA, K., KODAMA, I. \& TOYAMA J. (1989). Effects of propafenone on electrical and mechanical activites of single ventricular myocytes isolated from guinea-pig hearts. Br. J. Pharmacol., 97, 731-738.

ISENBERG, G. \& KLÖCKNER, U. (1982). Calcium tolerant ventricular myocytes prepared by preincubation in a 'KB medium'. Pflügers Arch., 395, 6-18.

KARAGUEUZIAN, H., FUJIMOTO, T., KOTOH, T., MCKULLEN, A. \& MANDEL, W. (1983). Suppression of ventricular arrhythmias by propafenone, a new antiarrhythmic agent, during acute myocardial infarction in the conscious dogs. A comparative study with lidocaine. Circulation, 66, 1190-1198.

KELLER, R., MEYER-ESTORF, G., BECK, O. \& HOCHREIN, H. (1978). Correlation between serum concentration and pharmacological effects on atrio-ventricular conduction time of the antiarrhythmic drug propafenone. Eur. J. Clin. Pharmacol., 13, 17-20.

KOHLHARDT, M. (1977). Der Einfluss von Propafenon auf den transmembranören $\mathrm{Na}^{+}$und $\mathrm{Ca}^{++}$Strom der Warblütter-Myokardfasermembran. In Forschritte in der Pharmakotherapie von Herzhythmusstörungen. ed. Hochrein, H., Hapke, H.J. \& Beck, O. pp. 35-58. Stuttgard: Fischer.

KOHLHARDT, M., SEIFERT, C. \& HONDEGHEM, L.M. (1983). Tonic and phasic $I_{\mathrm{Na}}$ blockade by antiarrhythmics: different properties of drug binding to fast sodium channels as judged from $V_{\max }$ studies with propafenone and derivatives in mammalian ventricular myocardium. Pflügers Arch., 396, 199-209.

KROEMER, H.K., FUNCK-BRENTANO, C., SILBERSTEIN, D.J., WOOD, A.J., EICHELBAUM, M., WOOSLEY, R.L. \& RODEN, D.M. (1989). Stereoselective disposition and pharmacologic activity of propafenone enantiomers. Circulation, 79, 1068-1076.
LEDDA, F., MANTELLI, L., MANZINI, S., AMERINI, S. \& MUGELLI, A. (1981). Electrophysiological and antiarrhythmic properties of propafenone in isolated cardiac preparations. J. Cardiovasc. Pharmacol., 315, 55-62.

LEE, K.S. \& TSIEN, R.W. (1983). Mechanism of calcium channel blockade by verapamil, D-600, diltiazem and nitrendipine in single dialysed heart cells. Nature, 302, 790-794.

MALECOT, C.O. \& TRAUTWEIN, W. (1987). On the relationship between Vmax of slow responses and Ca-current availability in whole-cell clamped guinea-pig heart cells. Pflügers Arch., 410, 15-22.

MALFATTO, G., ZAZA, A., FOSTER, M., SODOWICK, B., DANIOL, P. JR. \& ROSEN, M.R. (1988). Electrophysiologic, inotropic and antiarrhythmic effects of propafenone, 5-hydroxypropafenone and N-depropylpropafenone. J. Pharmacol. Exp. Ther., 246, 419-426.

MCDONALD, T.F., PELZER, D. \& TRAUTWEIN, W. (1980). On the mechanism of slow calcium channel block in heart. Pflügers Arch., 385, 175-179.

MITRA, R. \& MORAD, M. (1986). Two types of calcium channels in guinea-pig ventricular myocytes. Proc. Natl. Acad. Sci. U.S.A., 83, 5340-5344.

MULLER-PELZER, H., GREGER, G., NEUGEBAUER, G. \& HOLLMANN, M. (1983). Beta-blocking and electrophysiological effects of propafenone in volunteers. Eur. J. Clin. Pharmacol., 25, 831-833.

PELZER, D.W., TRAUTWEIN, W. \& MCDONALD, T.F. (1982). Calcium channel block and recovery from block in mammalian ventricular muscle treated with organic channel inhibitors. Pflügers Arch., 394, 97-105.

PHILIPSBORN, G.V., GRIES, J., HOFMANN, H.P., KREISKOTT, H., KRETZSCHMAR, R. \& MÚlLER, C.D. (1984). Pharmacological studies on propafenone and its main metabolite 5-hydroxypropafenone. Arzneim. Forsch., 34, 1489-1497.

SANGUINETTI, M.C. \& KASS, R.S. (1984). Voltage-dependent block of calcium channel current in the calf cardiac Purkinje fiber by dihydropyridine calcium channel antagonists. Circ. Res., 55, 336-348.

SATOH, H. \& HASHIMOTO, K. (1984). Effect of propafenone on the membrane currents of rabbit sino-atrial node cells. Eur. J. Pharmacol., 99, 185-191.

SCHLEPPER, M. (1987). Propafenone, a review of its profile. Eur. Heart. J., 8, Suppl A, 27-32.

TAMARGO, J. \& DELGADO, C. (1985). Electrophysiological effects of propafenone on isolated guinea-pig ventricular muscle and sheep Purkinje fibres. Eur. J. Pharmacol., 118, 331-340.

TRAUTWEIN, W., PELZER, D., MCDONALD, T.F. \& OSTERRIEDER, W. (1981). AQA 39, a new bradycardic agent which blocks myocardial calcium (Ca) channels in a frequency- and voltagedependent manner. Naunyn-Schmiedebergs Arch. Pharmacol., 317, $228-232$.

UEHARA, A. \& HUME, J.R. (1985). Interactions of organic calcium channel antagonists with calcium channels in single frog atrial cells. J. Gen. Physiol., 85, 621-647.

VALENZUELA, C., DELPON, E. \& TAMARGO, J. (1989). Electrophysiological interactions between mexiletine and propafenone in guinea-pig papillary muscles. J. Cardiovasc. Pharmacol., 14, $351-357$.

YATANI, A., BROWN, A.M. \& SCHWARTZ, A. (1986). Bepridil block of cardiac calcium and sodium channels. J. Pharmacol. Exp. Ther., 237, 9-17. 